\title{
Managing service innovation with cloud technology
}

\author{
Li-Cheng Chen $\cdot$ Chin-Yao Tseng
}

Published online: 12 November 2013

(C) International Network of Business and Management 2013

\begin{abstract}
The purpose of this paper is to identify what benefits cloud service solutions can offer leisure restaurants in Taiwan to gain a competitive marketing advantage. A cloud service solution refers to a self-service process that offers customers support with table reservation, dish ordering, and dining time at one finger-touch with a smartphone or portable device from anywhere, anytime. Based on the concept of service processes as part of service quality, delivering service through cloud technology is examined as a better solution for enhanced customer satisfaction. A qualitative method approach consisting of a Delphi technique and semi-structured interviews was undertaken with the IT consultants and application software developers to identify beneficial factors of cloud technology. The five beneficial factors identified are low expenses for supporting a marketing programme, prompt business response to market needs, differentiation from competitors, fast service processes with immediate useful information and enhanced customer value and relationship. The findings reveal that a cloud service solution is able to differentiate leisure restaurants from their competitors, as it is regarded as a direct marketing channel by smartphone end-users. The findings of this paper support the position that a cloud service solution is able to enhance customers' value and relationship with restaurants. This new service process solution has actively driven customer interaction with restaurants using a mobile device.
\end{abstract}

Keywords Cloud technology $\cdot$ Cloud service $\cdot$ Leisure restaurant $\cdot$ Service innovation

\footnotetext{
L.-C. Chen

Department of Hospitality Management, Tajen University, Pingtung, Taiwan e-mail: li_cheng@mail.tajen.edu.tw

C.-Y. Tseng ( $\square)$

Department of Food and Beverage Management, Yuanpei University, No. 306, Yuanpei Street, HsinChu 30015, Taiwan e-mail: chinyao@mail.ypu.edu.tw
} 


\section{Introduction}

Technology-driven innovation on service process exchange always plays an important role in facilitating or enabling organizations to obtain a competitive advantage in the marketplace (Bilderbeek et al. 1998). Service innovation using IT capabilities and competences can help organizations transform key business processes and practices by focusing on both internal operational efficiency and external customer self-service interactions (Bhatt and Grover 2005; Bilderbeek et al. 1998; Bilgihan et al. 2011). For example, cloud technology used as a self-service technology may be used for eliminating non-valued processes or reorganizing a solution to a problem in the hospitality industry. A cloud service solution has a significant relationship with competitive advantages for the hospitality industry, as it offers opportunities to increasingly meet customer expectations and provide more effective marketing strategies (Bilgihan et al. 2011; Law and Jogaratnam 2005; Piccoli 2008).

Cloud service solutions are a recent development, where self-service application has evolved from an online computer-driven application to a freestanding kiosk, and is now accessible with a portable or mobile device. For example, a person who books her movie tickets online through her mobile and just shows her mobile phone face to a scanner at the theatre. Self-service solution through a personal smartphone is considered a far superior type of customer service (Salmon 2011). This is because today's customers want control over how and when they interact with companies from anywhere, as they are time-starved and do not want to wait in long lines (Mastroberte 2011). More importantly, they want things now and are used to getting things from multiple channels (Mastroberte 2011). Cloud service solutions can fulfil the service of these customers' demands with effective marketing activities and promotions. Blair (2010) and Mastroberte (2011) also state that cloud service solutions can be a selling point and that the availability of this self-service solution in foodservice or lodging establishments is a competitive differentiator among customers, particularly younger generations (those aged between 18 and 34 years). Therefore, cloud service solutions are likely to be a proactive business model to adopt for hospitality organizations in today's business environment.

The purpose of this research is to explore what benefits cloud service solutions can offer leisure restaurants in Taiwan to gain a competitive marketing advantage. This research study has focused on service innovation theory with cloud technology adoption and the concept of value creation which are shown in Literature review section. Based on the concept of service processes as part of service quality, delivering service through cloud technology is examined as a better solution for enhanced customer satisfaction (Salmon 2011). In fact, this approach is the most important key to building customers' loyalty in today's marketplace (Salmon 2011). For example, the relationship between restaurants and customers can be initially established by a cloud service solution, which is able to provide immediate information of a restaurant's operation regarding table reservations, menu or even dish ordering. In addition, the restaurant/customer relationship can be further expanded with the restaurant's promotion of events during festive holidays or special promotions. Cloud service solutions can thus transform the business model 
to a more proactive type of customer-to-business relationship. This study explores this relationship and its benefits. The paper first examines contemporary literature on service innovation with cloud technology and value creation for customers in the self-service process. It describes the qualitative methods used. Findings are presented and analysed with a discussion on limitations and suggestions for further research.

\section{Literature review}

Service innovation with cloud technology

Service innovation approaches have continuously striven for better solutions to sustain a competitive advantage for the hospitality industry (Ottenbacher and Gnoth 2005). Customers are demanding and becoming sophisticated in their expectations of service every time they experience a service transaction and innovative service provision is one solution to satisfy them and retain their custom (Bilderbeek et al. 1998; Ottenbacher and Gnoth 2005). The forms of innovative service can be diversely delivered with new product or process, which is based on the concept of the four-dimensional model of service innovation (Bilderbeek et al. 1998). The fourdimensional model of service innovation refers to a bundle of capabilities and competences (human, technological and organisational) at the disposal of the client to organise a solution to a problem (Bilderbeek et al. 1998). In addition, new technology always plays a dominant and innovative role in supporting organisations to differentiate themselves from competitors (Bilderbeek et al. 1998; Bilgihan et al. 2011). Cloud technology can provide competitive marketing advantages for leisure restaurants in Taiwan.

Cloud technology used in service innovation has transformed the customer/ business relationship to a more customer-dominated one (Bilderbeek et al. 1998; Gopalani and Shick 2011), which means that customers are able to be more active in their interactions with the company than ever. Cloud technology solutions offer a model for enabling convenient, on-demand network access to a shared pool of configurable computing resources (e.g. network, servers, storages, applications and services) that can be rapidly provisioned and released with minimal management effort or service provider interaction (Han 2010 p.1). Cloud technology enhances a self-service solution, through innovative communication channels between the business and customers and also provides customers with effective marketing messages straight to their mobile device. This new technology can enable organisations to target new markets and provide opportunities to attract new segment of customers, who have unique needs throughout the purchase process utilising cloud technology (Gopalani and Shick 2011; Salmon 2011). Networkoriented customers engage in a self-service experience that makes the buying process easier, reducing service hassles and enhancing customer satisfaction (Gopalani and Shick 2011). Customers who have positive self-service experience are much more likely to be loyal and refer others to the brand (Gopalani and Shick 2011). Therefore, cloud technology has the potential to provide organisations with a 
competitive advantage by differentiating their specific brand and increasing the loyalty of self-service customers (Gopalani and Shick 2011; Ottenbacher and Gnoth 2005).

Value creation for customers in the self-service process

As a portable or smartphone device increasingly becomes popular in Taiwan, value creation for customers can occur in a given self-service process with cloud technology. Customer value is increasingly created in the self-service process of interaction and engagement with service providers, as the customer becomes a cocreator of value (Vargo and Lusch 2004; Woodruff and Flint 2006). The value is created when an offering is experienced and perceived positively by the customers (Payne et al. 2008; Prahalad and Ramaswamy 2000). Today's discerning customers engage in an interaction with service providers and seek their preferred experiences and service choices thus becoming co-creators and beneficiaries of value (Payne et al. 2008).

The value creation process involves three key elements: 1) the values companies can provide to their customers; 2) the values companies can receive from their customers; and 3) by successfully managing the value exchange, customers maximize their lifetime value in a process of co-creation or co-production (Payne and Frow 2005). This value exchange draws on the concept that to create such benefits companies should integrate their resources to clearly form the value proposition that explains to customers the relationship between the performance of the product or service, the fulfilment of the customer's needs, and the total cost to the customer over the customer relationship life cycle (Lanning 2000; Payne and Frow 2005).

Payne et al. (2008) have further explained that the process of creating the value proposition by the companies should consist of three main components: 1) customer value-creating processes; 2) supplier value-creating processes and 3) encounter processes. These three components structure the conceptual framework for the value creation process. In customer value-creating processes, customers are active players in achieving their particular goals by developing and personalizing their relationships with the service providers (Payne et al. 2008). It is noted that customers are able to learn to use and adapt the offerings of the service or product provider to their individual needs, usage situations and behaviours (Vargo and Lusch 2004). Value is thus embedded in customers' practices and that value can be created by the operand resources that service providers offer and the goodness of fit of these resources within the customers' overall activities (Normann 2001).

The relationship experience and customer learning are thus two important elements within the customer value-creating processes (Payne et al. 2008). The relationship experience involves cognition, emotion and behaviour (Payne et al. 2008). Cognition involves the customer assessing the benefits of a product or service from the perspective of privacy in the information search process (Holbrook and Hirschman 1982). Cloud service solutions are able to offer private interaction with goal-directed customers in the self-service process. Emotion has been broadly explained by (Bechman 1989) as relating to the importance to customers of the flow 
of fantasies, fun, personal feelings and characteristics of personality in the experience of consumption. Experiential consumption thus involves the aspects of contexts and symbols in the self-service process, which is different from the aspects of cognition discussed above. Behaviour is the actions of consumers based on their integration of cognitive information search process and emotional experiential consumption during the interaction with service providers.

Customer learning is a reflection of the relationship experience that involves customers in thinking, feeling and doing in respect to their role in value creation process. This learning process determines customer satisfaction and leads to the degree of customer involvement with service providers (Payne et al. 2008). More importantly, the result of this learning process is demonstrated by the changes within customers' attitudes and preferences towards particular service providers (Payne et al. 2008). These authors have further stressed that there are three types of customer learning including remembering, internalization and proportioning. Remembering refers to customers' level of attention to the service providers (Payne et al. 2008). Internalization refers to customers' interpretation about the messages and experiences they have experienced from the service providers (Payne et al. 2008). Proportioning refers to customers' learning reflection which involves a form of double-loop learning, which may change customers' behaviour so they perform new activities or disengage from existing practices (Argyris and Schon 1978; Payne et al. 2008).

Supplier value-creating processes, on the other hand, assist co-creation through the design and delivery of customer experiences and the facilitation of organisational learning (Payne et al. 2008). This is the value proposition offered by companies and designed based on the three elements: co-creation opportunities, planning and implementation metrics. Cloud service solution has met the requirements of value co-creation opportunities as this new technology provides a new way of interaction with customers that is developed based on the changes in customers' preferences and lifestyles. This solution allows service providers to increasingly utilise direct one-to-one marketing and customises their promotion programmes to meet the needs of each individuals. This solution is also planned and implemented based on the perspective of outside-in customer value, which is created and delivered over time as the relationship develops (Gronroos 1997; Payne et al. 2008). Organisational learning from the perspective of the firm offering the services or products can be diversely facilitated by knowledge management in which customer experiences and processes should be highly measured rather than solely focusing on the data of customer satisfaction (Payne et al. 2008). It is believed that service providers can obtain their competitive advantages with cloud service solution as this solution is developed based on the metrics of customers' preferences and lifestyles.

The encounter processes is an interface of two-way interactions and transactions between the customer and the service provider. This is the resources exchange practices in which the customer pays for the product/service, as well as the collaborative practices in which both parties jointly perform activities (Payne et al. 2008). This process also facilitates three functions of value creation including communication, usage and service. The communication encounter refers to the 
activities that customer can obtain benefits from as marketing messages can be mainly delivered through the use of printed medias or online service channels (Payne et al. 2008). Usage encounter refers to customer practices which support the customer's best utilisation of the service (Payne et al. 2008). Service encounter refers to customers' interactions with customer service personnel (Payne et al. 2008). These interactions begin with a promise of marketing messages in the communication process and end in the delivery of that promise. It is believed that a better encounter process design determines the better value the customer can create in the value creation process.

Cloud service solutions play an important role in facilitating customers to participate in the process of joint value creation and intention of their purchase behaviour is expected to be significantly influenced by this new technology solution. Therefore, the research question promoted by an analysis of the literature was, 'What benefits can cloud service solutions offer leisure restaurants in Taiwan to gain a competitive marketing advantage'.

\section{Methodology}

A qualitative method approach consisting of a Delphi technique and semi-structured interviews was used as this approach is suited to answering the exploratory research question (Creswell et al. 2006). Purposive and snowball sampling designs were used to collect and interpret data as the target population requires participants who have knowledge in the IT field and experience of cloud service (Zikmund 2003). Data saturation was also used to categorize and underpinning the concept of this study, as this technique supports the evidence of trustworthy findings when the same sorts of answers from interviewees start occurring and there is little on new information offered (Denzin and Lincoln 1994).

Delphi technique

The Delphi technique was initially used to help understand the definition of selfservice with cloud technology. Hsu and Sanford (2007) stress that the Delphi technique is a widely used method for gathering data from respondents within their domain of expertise when there is little or unknown knowledge about the topic of the research. In the Delphi technique, three IT consultants and two application software developers were purposefully selected and invited to participate in for this study. Consultants from the IT industry were selected from the recommendation of the researcher's previous colleagues as the researcher was working in the IT industry. Two application software developers were selected from the recommendation of the application software development company where the business focuses on location-based service integrating cloud technologies of data, location and positioning.

An open-ended question of 'Are you aware of self-service process with cloud technology (cloud service solution) that has been applied for restaurant industry? If so, please explain what it means to you?' was initially used to present a broad 
question at the beginning of research question. The responses from the IT consultants and application software developers were positive and they could easily describe it in terms such as, the 'It is a self-service process solution that offers customers support with table reservation, dish ordering, and dining time at one finger-touch with a smartphone or portable device from anywhere, anytime'.

The second question, 'From a marketing perspective, what would be the beneficial factors of cloud service solution for the leisure restaurant industry?' was used to gather a list of beneficial factors. These included low expenses for supporting a marketing programme, prompt business response to market needs, differentiation from competitors, fast service process with immediate useful information and enhanced customer value and relationship. This final consensus list was finally confirmed by the email communication from all aspects of respondents.

\section{Semi-structured interviews}

Semi-structured interviews were the second step used to understand and detail of how each of the five beneficial factors of cloud service solutions can offer leisure restaurants in Taiwan to gain a competitive marketing advantage. In the semistructured interviews, twenty-five smartphone end-users were purposefully selected and invited to participate in this study as this size of group is suitable to infer and represents the total population of the study under a budget and time control (Kuzel 1992; Maykut and Morehouse 1994). Those participants were mainly selected by the snowball process of one participant to another and they are all from Taiwan's north regions of Taipei and Taipei County as these regions are more likely to offer cloud service solutions for customer service (Zikmund 2003). Table 1 provides a summary of the five beneficial factors with semi-structured interview questions.

Table 1 Five beneficial factors with semi-structured interview questions

\begin{tabular}{|c|c|c|}
\hline & Five beneficial factors & Semi-structured interview questions \\
\hline 1. & $\begin{array}{l}\text { Low expenses for supporting a } \\
\text { marketing programme }\end{array}$ & $\begin{array}{l}\text { Q1. Have you ever received restaurants' marketing information } \\
\text { or special promotion on your smartphone? If you did, did you } \\
\text { consider this text-message (app) promotion more economical } \\
\text { and effective than any other print media such as direct mail } \\
\text { advertising (DM)? Please explain. }\end{array}$ \\
\hline 2. & $\begin{array}{l}\text { Prompt business response to } \\
\text { market needs }\end{array}$ & $\begin{array}{l}\text { Q2. Have you received festive special offers from restaurants } \\
\text { that you have been before? If you did, how did you respond } \\
\text { to this special offer? Please explain. }\end{array}$ \\
\hline 3. & Differentiation from competitors & $\begin{array}{l}\text { Q3. What did you think of restaurants offering cloud service in } \\
\text { comparison to restaurants not offering cloud service? }\end{array}$ \\
\hline 4. & $\begin{array}{l}\text { Fast service processes with } \\
\text { immediate useful information }\end{array}$ & $\begin{array}{l}\text { Q4. How did you respond to restaurants' immediate useful } \\
\text { information regarding to their web-based table reservation, } \\
\text { menu ordering, and dining time reservation? }\end{array}$ \\
\hline 5. & $\begin{array}{l}\text { Enhanced customer value and } \\
\text { relationship }\end{array}$ & $\begin{array}{l}\text { Q5. What has been the value of cloud service and restaurants } \\
\text { for you? Please explain. }\end{array}$ \\
\hline
\end{tabular}




\section{Analysis and discussion}

Demographic data in Table 2 indicate that there were more female $(64 \%)$ than male respondents $(36 \%)$. The majority of respondents were aged between 18 and 25 years $(60 \%)$, followed by age group of 26-35 years $(36 \%)$ and age group of 36-45 years (4\%). In relation to education, most respondents had bachelor's degree (72\%), followed by 2 and 5 years college $(20 \%)$ and master degree $(8 \%)$.

The objective of this study was to understand what beneficial factors cloud service solutions can offer leisure restaurants in Taiwan to gain a competitive marketing advantage. These beneficial factors are low expenses for supporting a marketing programme, prompt business response to market needs, differentiation from competitors, fast service process with immediate useful information and enhanced customer value and relationship. The demographic data reveal that the sample of smartphone end-users comprised a young and higher educated, female population and they mainly come from Generation Y (those born between the years of 1977 and 1997, aged below 36 years). This could infer that young and females are more likely to use mobile devices and cloud technology to search for restaurant options.

The results from Question 1 indicate that fifteen interviewees $(60 \%)$ had installed free application software in their smartphones, which frequently receive a range of restaurants' marketing information or special promotion. As they installed this free application software voluntarily, they preferred to receive this sort of immediate marketing information and also agreed that this is an economical and effective way of marketing product. Many scholars also support that cloud service solution is an extension of innovative web-based applications in online marketing, which is a cost-effective solution to building a new business model that includes a new direct marketing channel (Chung and Buhalis 2008; Gopalani and Shick 2011; Ip et al. 2011). As one interviewee said:

One female aged between 18 and 25 years said '...I would rather receive immediate marketing information than direct mail advertising (DM) on my hand,... because I can respond it immediately, or delete it if I don't like it...'.

Table 2 Summary of demographic data $(n=25)$

\begin{tabular}{llll}
\hline Variable & Category & $F$ & $(\%)$ \\
\hline Gender & Male & 9 & 36 \\
& Female & 16 & 64 \\
Age & $18-25$ years & 15 & 60 \\
& $26-35$ years & 9 & 36 \\
Academic qualification & $36-45$ years & 1 & 4 \\
& 2 and 5 years college & 5 & 20 \\
& Bachelor & 18 & 82 \\
\hline
\end{tabular}


The results from Question 2 indicate that all interviewees had received special offers from previously visited restaurants. The responses to special offers for those, who had visited restaurants, offered a consensus view around delicious foods as the most important attractor. Discount price was not their top priority to be considered when revisiting restaurants. This may alert managers of leisure restaurants that prompt business response to market is important but unique type and quality of delicious foods are more important factors to retain customers. This could be that although cloud service solution can enable leisure restaurants directly and economically to the targeted customers, customers always measure what they can get from the product/service comparing to what they have to pay for it (Levitt, 1969; Lovelock, 1995; Xiao et al., 2012). The statement below illustrates this view:

All respondents said '...In some cases, I may pay some attention to discount price offerings, ...but in most cases, unique type and quality of delicious foods or beautiful environment (e.g. mountain view) came first when I considered to revisiting the same restaurants...'.

The results from Question 3 indicate that all interviewees had a consensus on the positive side of cloud service solutions offering self-service that can save their time with immediate restaurant information. More importantly, surfing on the internet for restaurant reservation with their smartphones was exciting and satisfying for them. It is definitely a differentiator from their competitors for restaurants as customers are keen to experience this service innovation. This could be that young and higher educated people (Generation Y) are fascinated by novelty and in trying something new, especially new technology applications (Mastroberte, 2011). The statement below illustrates this perspective:

All respondents said '...I would be willing to use self-service with cloud technology... This was for fun and cool... Of course this can save me a lot of time in long lines waiting...'.

The results from Question 4 indicate that all interviewees were quite practical to their dining experience at restaurants as they all responded that cloud self-service was an option for them to choose a restaurant. They appreciated the fast service process with immediate useful information this new technology offered, but determination of final choice was dependent on other factors such as comments from previous customers. For example, word-of-mouth through friends had a major influence on their decision making as did comments left on the public food forum.

However, some interviewees had doubts about the operation of this new technology in terms of missing reservations and inconsistent dish ordering, as they did make a telephone call to reconfirm the time of table reservation with restaurant staff. This shows that cloud service solutions can provide opportunities for leisure restaurants to directly interact with their customers, but trust in the service process as perceived by customers need to be resolved. Other scholars also support that adoption of new technology can be influenced by the individual beliefs about usefulness and ease of use of that technology (Lewis et al. 2003). 
One female aged between 36 and 45 years strongly said '... I liked to get fast service process with immediate useful information about restaurants, but as I still don't trust cloud technology,... so I preferred to make a double confirmation with a phone call personally...'

The results from Question 5 indicate that all interviewees had perceived a value of customer relationship from the restaurants in the cloud service process as they regularly received promotion messages which were customised to meet the needs of their preferences. For example, special offers for early bird reservation and a good table position on Valentine's Day. More importantly, customer's voice can be easily and directly collected and responded by after service platform or website bulletin of the leisure restaurants. This is supported by some scholars that each instance of value creation is unique to and can only be addressed from the perspective of an individual service system (Gronroos and Ravald 2011; Vargo and Akaka 2009) and is supported by the following statement:

One male aged between 26 and 35 years said '... A restaurant sent me the message containing the special offers with my preferences for revisiting the restaurant again... They had history of my dinning preferences...'.

\section{Limitations}

There are four limitations to this study. First, restaurants' managers were not invited to participate in this study and this has caused bias. Further research could be undertaken on the perspectives of restaurant managers. Second, the small sample size may be considered a limitation to the research. Further research could include a quantitative approach with a large sample of smartphone end-users. Third, all respondents came from the northern regions of Taiwan. This could misrepresent the results of such a cloud service study. Further research could include other regions of Taiwan. Finally, this study has not addressed some factors, such as security and privacy issues, availability of wireless infrastructure, and quantity of smartphone users, which may have an influence on the applications of cloud service. A further study focusing on these factors would be instructive.

\section{Conclusion}

Three conclusions may be drawn from this exploratory study. First, this study has identified the five beneficial factors that cloud service solutions can offer leisure restaurants in Taiwan to gain a competitive marketing advantage. They are low expenses for supporting a marketing programme, prompt business response to market needs, differentiation from competitors, fast service process with immediate useful information and enhanced customer value and relationship. These findings have some implications for marketing and IT planners in the leisure restaurant industry as they are competitive advantages of IT investment (Bilgihan et al. 2011). Second, the findings indicate that a cloud service solution is regarded as a direct 
marketing channel by smartphone end-users. This is significant that leisure restaurants can work together with marketing companies to maximize use of cloud technology for sustainable competitive marketing advantages. Third, there are still trust issues related to the use of this technology.

In addition to demographic findings, young and higher educated females are the targeted customers who mainly search for delicious foods. More importantly, as customers are demanding and becoming sophisticated in their expectations of service transactions, the unique type and quality of delicious food and restaurant setting and ambiance are the key factors to attract and retain them. Although cloud service has naturally confined some unintentional difficulties, it would provide leisure restaurants a better competitive marketing advantage in Taiwan, particular Generation Y cohort.

This study makes a contribution to knowledge within Taiwanese leisure restaurant context as service innovation with cloud technology is a new application for this industry. The findings indicate that a cloud service solution is able to enhance customers' value and relationship with restaurants. This new service process solution has actively driven the customer interaction with the restaurant using a mobile device. These findings offer a good reference point for managers of leisure restaurants in Taiwan when considering enhancement of their service processes with cloud technology.

\section{References}

Argyris, C., \& Schon, D. (1978). Organizational learning: a theory of action perspective. Massachusetts: Addison Wesley.

Bechman, S. C. (1989). Emotions and consumer behaviour. In P. E. Earl (Ed.), The Elgar companion to consumer research and economic psychology (pp. 182-187). Cheltenham: Edward Elgar.

Bhatt, G. D., \& Grover, V. (2005). Types of information technology capabilities and their role in competitive advantage: an empirical study. Journal of Management Information Systems, 22(2), 253-277.

Bilderbeek, R., Hertog, P., Marklund, G. \& Miles, I. (1998). Services in innovation: knowledge intensive business services (KIBS) as co-producers of innovation. STEP group, SI4S Report no.3.

Bilgihan, A., Okumus, F., Nusair, K., \& Kwun, D. (2011). Information technology applications and competitve advantage in hotel companies. Journal of Hospitality and Tourism Technology, 2(2), $139-154$.

Blair, A. (2010). A new era for self-service: shifting consumer expectations, a brightening economy, and a bevy of up-and-coming applications kick hospitality self-service back into gear. http://c3185012. r12.cf0.rackcdn.com/v3-docs/70da7a459381dbe9686b8ac5851b54c0/2010-hospitality-self-servicetechnology-study.pdf. Accessed 30 June 2012.

Chung, J. Y., \& Buhalis, D. (2008). Information needs in online social networks. Journal of Information Technology and Tourism, 10(4), 267-281.

Creswell, J. W., Shope, R., Clark, L. P., \& Green, O. (2006). How interpretive qualitative research extends mixed methods research. Mid-South Educational Research Association, 13(1), 1-11.

Denzin, N. K., \& Lincoln, Y. S. (1994). Entering the field of qualitative research. In N. K. Denzin \& Y. S. Lincoln (Eds.), Handbook of qualitative research (pp. 1-17). Thousand Oaks: Sage.

Gopalani, A., \& Shick, K. (2011). The service-enabled customer experience: a jump-start to competitive advantage. Journal of Business Strategy, 32(3), 4-12.

Gronroos, C. (1997). Value-driven relational marketing: from products to resources and competencies. Journal of Marketing Management, 13, 407-419. 
Gronroos, C., \& Ravald, A. (2011). Service as business logic: implications for value creation and marketing. Journal of Service Management, 22(1), 5-22.

Han, Y. (2010). On the clouds: a new way of computing. Information Technology and Libraries, 29(2), 87-92.

Holbrook, M. B., \& Hirschman, E. C. (1982). The experiential aspects of consumption: Consumer fantasies, feeling, and fun. Journal of Consumer Research, 9, 132-140.

Hsu, C. C., \& Sanford, B. A. (2007). The Delphi Technique: Making sense of consensus. Practical Assessment Research and Evaluation, 12(10), 1-8.

Ip, C., Leung, R., \& Law, R. (2011). Progress and development of information and communication technologies in hospitality. International Journal of Contemporary Hospitality Management, 23(4), 533-551.

Kuzel, A. J. (1992). Sampling in qualitative inquiry. In B. F. Crabtree \& W. L. Miller (Eds.), Doing qualitative research (pp. 31-44). Newbury Park: Sage.

Lanning, M. J. (2000). Delivering profitable value: a revolutionary framework to accelerate growth, generate wealth, and rediscover the heart of business. Massachusetts: Perseus Publishing.

Law, R., \& Jogaratnam, G. (2005). A study of hotel information technology applications. International Journal of Contemporary Hospitality Management, 17(2), 170-180.

Levitt, T. (1969). The marketing mode: pathways to corporate growth. New York: McGraw-Hill.

Lewis, W., Agarwal, R., \& Sambamurthy, V. (2003). Sources on influence on beliefs about information technology use: An empirical study of knowledge workers. MIS Quarterly, 27(4), 657-678.

Lovelock, C. (1995). Competing on service: Technology and teamwork in supplementary services. Planning Review, 23, 32-39.

Mastroberte, T. (2011). Multi-media and customer controlled: hotels, restaurants \& customers rapidly embrace migration of self-service apps onto new platforms. http://ncrpr.ncr.com/web/rsdmkt/docs/ Hospitality_Technology_Report.pdf. Accessed 30 June 2012.

Maykut, P., \& Morehouse, R. (1994). Beginning qualitative research: a philosophic and practical guide. London: Falmer Press.

Normann, R. (2001). Reframing business: when the map changes the landscape. England: Wiley.

Ottenbacher, M., \& Gnoth, J. (2005). How to develop successful hospitality innovation. Cornell Hotel and Restaurant Administration Quarterly, 46(2), 205-222.

Payne, A., \& Frow, P. (2005). A strategic framework for customer relationship management. Journal of Marketing, 69, 167-176.

Payne, A. F., Storbacka, K., \& Frow, P. (2008). Managing the co-creation of value. Journal of the Academy of Marketing Science, 36(1), 83-96.

Piccoli, G. (2008). Information technology in hotel management: a framework for evaluating the sustainability of IT-dependent competitive advantage. Cornell Hospitality Quarterly, 49(3), 282-296.

Prahalad, C. K., \& Ramaswamy, V. (2000). The future of competition: co-creating unique value with customer. Boston: Harvard Business School.

Salmon, K. (2011). Hospitality redefined: how self-service technology is transforming the industry for the mobile generation. http://www.ariane.com/NewsAdmin/2011_Self-Service_Impact_on_Hospitality_ for_MobileGen.pdf. Accessed 30 June 2012.

Vargo, S. L., \& Akaka, M. A. (2009). Service-dominant logic as a fundation for service science: clarifications. Service Service Science, 1(1), 32-41.

Vargo, S. L., \& Lusch, R. F. (2004). Evolving to a new dominant logic for marketing. Journal of Marketing, 68(1), 1-17.

Woodruff, R. B., \& Flint, D. J. (2006). Marketing's service-dominant logic and customer value. In R. F. Lusch \& S. L. Vargo (Eds.), The service dominant logic of marketing: dialog, debate and directions (pp. 183-195). New York: M.E. Sharpe.

Xiao, L., Wang, F., \& Wang, Z. (2012). Research on the relationship between customer value of social network service and customer loyalty. Advances in Intelligent and Soft Computing, 117, 27-32.

Zikmund, W. G. (2003). Business research methods (7th ed.). Ohio: Thomson South-Western. 